\title{
Literature Review : Hubungan Pengetahuan Asma dengan Upaya Pencegahan Kekambuhan pada Penderita Asma
}

\author{
Ana Khaitul Sulistiani ${ }^{1 *}$, Dian Kartikasari ${ }^{2}$ \\ ${ }^{1,2}$ Program Studi Sarjana Keperawatan, Universitas Muhammadiyah Pekajangan Pekalongan, \\ Indonesia \\ *email :Anakhaitulsulistiani@gmail.com
}

\begin{abstract}
Knowledge is the result of knowing someone by sensing certain objects, sensing can occur through the five human sense, namely the senses of sight, hearing, smell, taste, and touch. Good knowledge can couse good preventive behaviors. Early prevention is the only thing that can be done to avoid the recurrebce of asthma. The prevention is done to minimize the risk of asthma attacks. This literature review aimed to determine the correlation between knowledge about asthma and the prevention of recurrence of asthma. This literature Review accessed PUBMED by combining the keywords "Knowledge" and "Prevention Asthma". Participants in this study were patients with asthma who had a P-Value of 0,000 . The Results showed that there was a correlation between knowledge about asthma and efforts to prevent the recurrence of asthma. This study is expected to be a reference for hospitals or health centers to increase educational activities and knowledge about asthma.
\end{abstract}

Keyword: Asthma Knowledge, Asthma Prevention

\begin{abstract}
Abstrak
Pengetahuan merupakan hasil dari tahu seseorang dengan cara melakukan penginderaan terhadap obyek tertentu, penginderaan dapat terjadi melalui panca indra manusia yaitu dengan indra penglihatan, pendengaran, penciuman, rasa dan raba. Pengetahuan yang baik maka perilaku pencegahan juga akan baik. Pencegahan sejak dini merupakan satu-satunya hal yang bisa dilakukan untuk menghindari terjadinya penyakit asma, pencegahan dilakukan untuk memperkecil risiko terjadinya serangan asma. Literature Riview ini bertujuan untuk Mengetahui hubungan pengetahuan tentang asma dengan upaya pencegahan kekambuhan pada penderita asma. Literature Review ini mengakses database melalui PUBMED dengan mengkombinasikan kata kunci "Knowledge" AND 'Prevention Asthma". Partisipan pada studi ini adalah pasien dengan penderita asma yang didapatkan P-Value 0,000, diperoleh dengan menggunakan metode melalui cross sectional. Hasil Literature Review ini menunjukkan bahwa adanya hubungan pengetahuan tentang penyakit asma dengan upaya pencegahan kekambuhan penderita asma.Studi ini diharapkan dapat menjadi referensi pihak Rumah Sakit atau Puskesmas untuk meningkatkan kegiatan terhadap pendidikan serta pengetahuan tentang penyakit asma.
\end{abstract}

Kata Kunci: Pengetahuan Asma, Pencegahan Asma

\section{Pendahuluan}

Asma merupakan penyakit jangka panjang yang menyerang saluran pernapasan, menyebabkan udara masuk dan keluar melalui saluran kecil paru-paru. Pada asma saluran udara menyempit dan menyebabkan kesulitan bernafas dan beberapa perubahan terjadi pada saluran pernapasan penderita asma[1].

Menurut data dari Global Initiative for Asthma[2]peristiwa asma dari bermacam negeri dikatakan 1- 18\% serta diperkirakan 300 juta orang di segala dunia mengidap 


\section{Prosiding Seminar Nasional Kesehatan 2021 Lembaga Penelitian dan Pengabdian Masyarakat Universitas Muhammadiyah Pekajangan Pekalongan}

asma. Menurut World Health Organization (WHO, 2016) prevalensi asma saat ini 235 juta orang di dunia menderita asma.Di negara berkembang, penyakit ini kurang terdiagnosis dan angka kematiannya melebihi $80 \%$. Di Amerika Serikat, menurut data tahun 2016 dari National Center for Health Statistics (NCHS), prevalensi asma berdasarkan usia sebesar 7,4\% pada dewasa dan pada anak-anak 8,6\%, berdasarkan jenis kelamin 6,3\% pada laki-laki dan 9,0\% pada perempuan, dan berdasarkan ras adalah ras kulit putih sebesar 7,6\%, dan ras kulit hitam 9,9\%. Menurut [3]berpengaruh pada disabilitas dan kematian dini terutama pada anak usia 10-14 tahun dan orangtua usia 75-79 tahun.

Berdasarkan Global Intiative for asthma pada tahun 2016pravalensi asma yang ada di Asia Tenggara sebesar 3,3\% dimana sebanyak 17,5 juta penderita asma dari 529,3 juta total populasi, Indonesia menempati urutan ke-19 di dunia penyebab kematian akibat asma dan menyumbang 1 dari 12 kematian asma penyakit tidak menular.

Peneliti melakukan penelitian ini untuk mengetahui hubungan pengetahuan tentang penyakit asma dengan upaya pencegahan kekambuhan penderita asma. Dalam penelitian ini dijelaskan bahwa mengapa peneliti melakukan penelitian yaitu untuk mengetahui apakah ada hubungan pengetahuan tentang penyakit asma dengan upaya pencegahan kekambuhan pada penderita asma .

Peneliti menyelesaikan masalah dengan 5 artikel yang berhubungan dengan adanya artikel yang berisi hubungan pengetahuan tentang asma dengan upaya pencegahan kekambuhan penderita asma.Upaya pencegaha agar penderita tidak mengalami kekambuhan penyakit asma selain dengan mencegah pemicu asma yaitu dengan memberikan informasi untuk meningkatkan pengetahuan tentang penyakit asma.

\section{Metode}

Strategi pencarian artikel pada penelitian ini dengan menuliskan kata kunci dalam Bahasa Indonesia "Pengetahuan" DAN "Pencegahan asma" serta menuliskan kata kunci dalam Bahasa Inggris "Knowledge" AND "Prevention Asthma". Database yang digunakan oleh peneliti yaitu Google Scholar dan dan PUBMED (Pemilihan artikel yang akan diteliti yaitu artikel dengan terbitan 10 tahun terakhir 2011-2021. Peneliti menggunakan instrumen Cross sectional dari JBI (The Joanna Briggs Institute).

\section{Hasil dan Pembahasan}

\section{Hasil}

1) Responden Pengetahuan Penderita Asma

Berdasarka dari hasil berbagai Literature Review didapatkan ada 5 artikel responden yang dari berbagai macam terbitan tahun penelitian yaitu dengan berpengetahuan baik, cukup, dan kurang sebagai berikut : 


\section{Prosiding Seminar Nasional Kesehatan 2021 Lembaga Penelitian dan Pengabdian Masyarakat Universitas Muhammadiyah Pekajangan Pekalongan}

Table 3.1 berdasarkan pengetahuan penderita asma $(n=306)$

\begin{tabular}{|c|c|c|c|c|c|c|c|}
\hline \multirow{3}{*}{ Penulis } & \multicolumn{5}{|c|}{ Pengetahuan } & & \\
\hline & Tahun & \multicolumn{2}{|c|}{ Baik } & \multicolumn{2}{|c|}{ Cukup } & \multicolumn{2}{|c|}{ Kurang } \\
\hline & & $F$ & $\%$ & $\mathrm{~F}$ & $\%$ & $\mathrm{~F}$ & $\%$ \\
\hline Heni Triana,dkk & 2014 & 1 & $32,4 \%$ & 8 & $52,9 \%$ & 5 & $14,7 \%$ \\
\hline Arin Satria,dkk & 2011 & 4 & $8 \%$ & 23 & $49 \%$ & 20 & $43 \%$ \\
\hline Rita Astuti,dkk & 2018 & 9 & $81,2 \%$ & NM & NM & 16 & $18,8 \%$ \\
\hline Samsul Qomar & 2018 & 36 & $51,4 \%$ & NM & NM & 34 & $48,6 \%$ \\
\hline Elfira Sri Futriani & 2018 & 34 & $48,6 \%$ & NM & NM & 36 & $51,4 \%$ \\
\hline $\begin{array}{l}\text { Total masing-masing } \\
\text { pengetahuan }\end{array}$ & & 154 & $44,32 \%$ & 41 & $20,38 \%$ & 111 & 35,3 \\
\hline Total responden $(\mathrm{N})$ & & & 306 & & & & \\
\hline
\end{tabular}

NM : Note Mention In Article

Berdasarkan hasil Literature Review pada 5 artikel responden dalam pengetahuan tentang penyakit asma berhubungan dengan upaya pencegahan kekambuhan pada penderita asma berdasarkan pengetahuan diperoleh hasil distribusi frekuensi dan presentase. Responden berpengetahuan baik sebanyak $154(44,32 \%)$, responden berpengetahuan cukup sebanyak 41 (20,38\%), sedangkan responden berpengetahuan kurang sebanyak 111 (35,3\%). Maka dapat disimpulkan bahwa hasil frekuensi berpengetahuan baik lebih banyak dibandingkan berpengetahuan cukup atau kurang.

2) Pencegahan Kekambuhan

Berdasarkan dari ari hasil Literature Review didapatkan 5 artikel responden dengan upaya pencegahan kekambuhan baik, cukup, dan kurang sebagai berikut:

Table 3.2 berdasarkan pencegahan kekambuhan $(n=306)$

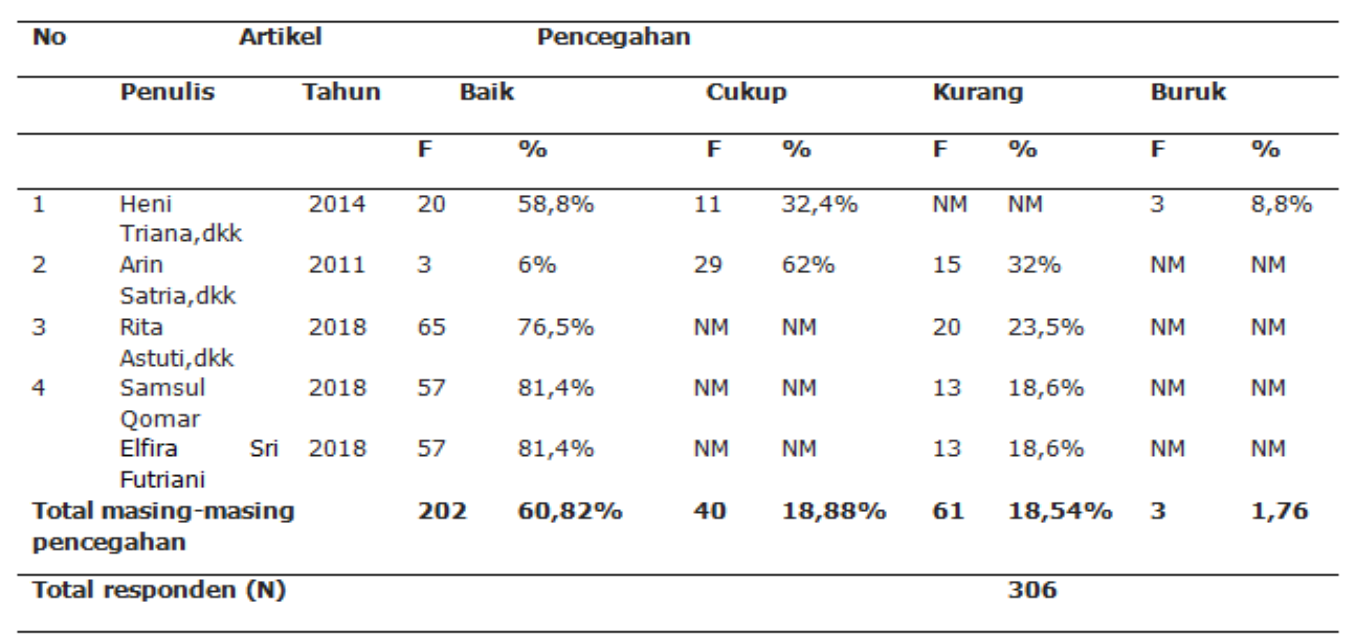

NM : Note Mention In Article 


\section{Prosiding Seminar Nasional Kesehatan 2021 Lembaga Penelitian dan Pengabdian Masyarakat Universitas Muhammadiyah Pekajangan Pekalongan}

Berdasarkan hasil Literature Riview pada 5 artikel responden dalam pengetahuan tentang penyakit asma berhubungan dengan upaya pencegahan kekambuhan pada penderita asma berdasarkan upaya pencegahan kekambuhan diperoleh hasil distribusi frekuensi dan presentase. Responden berupaya dalam pencegahan kekambuhan baik sebanyak $202(60,82 \%)$ responden dengan upaya pencegahan cukup sebanyak $40(18,88 \%)$, responden dengan upaya pencegahan kurang sebanyak $61(18,54 \%)$, sedangkan responden dengan upaya pencegahan buruk sebanyak $3(1,76 \%)$. Maka dapat disimpulkan bahwa hasil frekuensi upaya pencegahan kekambuhan baik lebih banyak dibandingkan berpengetahuan cukup, kurang atau buruk.

3) Hubungan pengetahuan dan upaya pencegahan kekambuhan

Berdasarkan dari hasil Literature Review didapatkan 5 artikel responden dengan hubungan pengetahuan dan upaya pencegahan kekambuhan baik, cukup, dan kurang didapatkan sebagai berikut :

Tabel 3.3 hubungan pengetahuan dan upaya pencegahan kekambuhan penderita asma

\begin{tabular}{cccc}
\hline \multicolumn{5}{c}{ Hubungan Pengetahuan dan Upaya Pencegahan Kekambuhan } \\
\hline No & Artikel & Tahun & P-value \\
\hline 1 & Heni. Triana_dkk & 2014 & 0,006 \\
2 & Arin. Satriaddkk & 2011 & 0,000 \\
3 & Rita Astuti_dkk & 2018 & 0,02 \\
4 & Samsul Qomar. & 2018 & 0,300 \\
5 & Elfira Sri Futriani. & 2018 & 0,300 \\
\hline
\end{tabular}

Berdasarkan hasil Literature Review pada 5 artikel responden dalam pengetahuan tentang penyakit asma berhubungan dengan upaya pencegahan kekambuhan pada penderita asma berdasarkan upaya pencegahan kekambuhan diperoleh hasil P-value. Maka dapat disimpulkan bahwa terdapat hubungan pengetahuan dan upaya pencegahan kekambuhan diperoleh dengan nilai Pvalue $<0,05$.

\section{Pembahasan}

1) Pengetahuan

Berdasarkan analisa data yang dilakukan 5 artikel bahwa pengetahuan sangat penting untuk masyarakat, pengetahuan yang kurang sangat berpengaruh pada kesembuhan penderita asma.Berdasarkan kekambuhan asma disebabkan karena faktor pengetahuan. Pengetahuan yang kurang sendiri disebabkan karena kurangnya kesadaran masyarakat untuk mendapatkan informasi tentang asma yang bersumber dari media cetak, masyarakat relative kurang berinteraksi dengan orang lain sehingga menyebabkan masyarakat menerima informasi relative kecil dengan pengetahuan yang cukup maka 


\section{Prosiding Seminar Nasional Kesehatan 2021 Lembaga Penelitian dan Pengabdian Masyarakat Universitas Muhammadiyah Pekajangan Pekalongan}

menjadikan masyarakat tinggi terhadap kemampuanya dalam memahami asma [4].

Menurut [5]tingkat pengetahuan yang baik memperngaruhi frekuensi kejadian asma karena dengan sikap baik mampu bertindak melakukan pencegahan penyakit asma yang berulang, tingkat sikap yang baik mempengaruhi bagaimana keluarga berusaha menjaga kesehatan keluarga karena dengan sikap yang baik akan mengarahkan keluarga untuk nertindak melakukan pencegahan terhadap berbagai penyakit khususnya asma.

\section{2) Upaya Pencegahan Kekambuhan Asma}

Menurut [5]pencegahan merupakan salah satu hal yang dilakukan untuk meghindari terjadinya penyakit asma, usaha pencegahan dapat dilakukan untuk mencegah kemungkinan terjadinya serangan penyakit asma ialah menerapkan pola hidup sehat dan menjaga kebersihan lingkungan, selain itu dapat menghindari faktor-faktor yang menyebabkan terjadinya serangan asma dengan menjaga kesehatan, menghindari faktor pemicu dan menggunakan obat asma.

Dalam upaya pencegahan perlunya dukungan keluarga dalam memotivasi penderita untuk melakukan usaha dalam mencegah kekambuhan, sebagian besar penderita tahu bagaimana cara mencegah kekambuhan asma tetapi kemauan dan motivasi yang kurang yang ada pada dirinya. Penderita yang mengalami kekambuhan jarang disebabkan karena adanyafaktor lingkungan yang baik motivasi dan dukungan dari keluarga termasuk dalam perawatan pencegahan kekambuhan serta patuhnya penderita dengan anjuran dari tenaga kesehatan untuk melakukan pencegahan asma itu sendiri [4].

3) Hubungan Pengetahuan dan Upaya Pencegahan

Berdasarkan hasil analisa data yang dilakukan dari 5 artikel didapatkan hasil 3 artikel ada hubungan pengetahuan tentang penyakit asma dengan upaya pencegahan kekambuhan penderita asma dan didapatkan 2 artikel tidak ada hubungan pengetahuan tentang penyakit asma dengan upaya pencegahan kekambuhan penderita asma. Menurut [3] terdapat hubungan pengetahuan tentang penyakit asma dengan upaya pencegahan kekambuhan penderita asma dikarenakan tingkat pendidikan respoden yang rendah dan jauhnya dari perkotaan didukung oleh kurangnya informasi tetang asma mendukung pengetahuan mereka tentang penyakit asma menjadi rendah juga, upaya pencegahan yang kurang, kondisi ini disebabkan karena kesalahfahaman penderita terhadap beberapa hal yang berkaitan dengan upaya pencegahan kekambuhan asma, sebagian besar penderita asma memiliki persepsi yang salah terhadap kerja yang berlebihan, penderita menganggap berkumpul dengan perokok dan pemakaian masker bukan pemicu kekambuhan asma.

Terdapat hubungan pengetahuan tentang penyakit asma dengan upaya pencegahan kekambuhan penderita asma disebabkan banyaknya penderita dengan berpengetahuan cukup dan upaya pencegahan kekambuhan asma yang buruk seperti tidak menghindari suhu yang dingin atau lembab, tidak mengkonsumsi obat yang diberikan dokter, tidak menghindari lingkungan kerja 


\section{Prosiding Seminar Nasional Kesehatan 2021 Lembaga Penelitian dan Pengabdian Masyarakat Universitas Muhammadiyah Pekajangan Pekalongan}

dan tempat yang banyak mengandung polusi udara sehingga upaya pencegahan tidak dilakukan secara efektif[6].

Sedangkan menurut artikel yang didapatkan dari [7] terdapat hubungan pengetahuan tentang penyakit asma dengan upaya pencegahan kekambuhan penderita asma disebabkan karena kurangnya pengetahuan yang kurang yang diterima di masyarakat, beberapa penderita menyebutkan belum pernah mendapatkan penyuluhan tentang asma sehingga menyebabkan infomasi yang mereka terima tentang penyakit asma relative sedikit sehingga penderita tidak melakukan upaya pencegahan kekambuhan asma dengan baik.

Di dapatkan 2 artikel tidak ada hubungan pengetahuan tentang penyakit asma dengan upaya pencegahan kekambuhan penderita asma menurut [1], [8]disebabkan sebagian besar penderita asma memiliki pengetahuan yang kurang tentang penyakit asma, tingkat pendidikan yang rendah sehingga penderita tidak mengetahui jelas tentang penyakit asma, namun tingkat pencegahannya yang tinggi karena penderita sudah mengalami penyakit asma cukup lama sehingga mereka sudah memiliki pengalaman bagaimana cara melakukan pencegahan terhadap penyakit asma supaya tidak kambuh seperti terkena debu dan cuaca dingin.

Pengetahuan kurang tidak akan membantu penderita untuk mencegah kekambuhan, semakin penderita berpengetahuan tinggi tentang asma maka penderita akan tahu bagaimana bersikap pada keadaan tersebut dan kekambuhan asma dapat diminimalkan. Pengetahuan tentang pencegahan asma merupakan salah satu yang bisa dilakukan adalah harapan pola hidup sehat, menjaga lingkungan bersih dari faktor penyebab terjadinya serangan asma[4].

Menurut [5]sikap sangat menentukkan usaha untuk menjaga agar tidak terjadi kekambuhan asma dan juga bergantung pada pengetahuan penderita terhadap penyakitnya, karena dengan pengetahuanya tersebut penderita memiliki alas an dan landasan untuk memilih dan menentukkan. Informasi dan pengetahuan tentang asma sangat penting dimana yang harus diajarkan kepada penderita adalah mengenalkan faktor pemicu serangan asma serta pemahaman tentang pencegahan, perawatan dan kerja obat asma, strategi untuk mengurangi gejala, dampak asma, dan gaya hidup serta kekambuhan asma.

Seperti yang disampaikan oleh [9]Pendidikan atau pengetahuan kepada penderita atau keluarga tentang penyesuaian gaya hidup dan kepatuhan terhadap pengobatan dapat membantu mencapai managemen yang optimal.dengan pengetahuan tinggi maka seseorang akan cenderung untuk mendapatkan informasi yang semakin banyak tentang kesehatan, orangtua atau keluarga yang memiliki pendidikan tinggi dapat mempengaruhi asma dengan cara mengindari makanan dan aktivitas yang dapat menyebabkan kekambuhan asma. Hal ini sejalan dengan penelitian yang dilakukan oleh [10]yang menyatakan bahwa pengetahuan tentang penyakit asma perlu diketahui masyarakat umum, sehingga untuk meminimalisasi faktor pencetus asma bagi penderita. 


\section{Prosiding Seminar Nasional Kesehatan Lembaga Penelitian dan Pengabdian Masyarakat Universitas Muhammadiyah Pekajangan Pekalongan}

Hasil Penelitian ini sejalan dengan[4]teori yang mengemukakan bahwa kurangnya pengetahuan penderita dan masyarakat tentang asma dan mengganggap asma merupakan penyakit tidak bisa disembuhkan, kurang upaya untuk melaksnakan pencegahan serangan asma dirumah, tidak telihat adanya usaha menghidari allergen. Hal tersebut dapat mengakibatkan pada kekambuhan penderita asma.

\section{Kesimpulan}

Berdasarkan responden yang didapatkan dari 5 artikel yaitu berdasarkan pengetahuan penderita asma paling banyak dengan berpengetahuan baik 154 (44,32\%), dibanding berpengetahuan cukup41 (20,38\%), atau kurang111 (35,3\%), Berdasarkan upaya pencegahan kekambuhan penderita asma paling banyak didapatkan dengan upaya pencegahan kekambuhan baik $202(60,82 \%)$ dibanding upaya pencegahan kekambuhan cukup40 (18,88\%), atau kurang61 (18,54\%), Terdapat hubungan antara pengetahuan tentang penyakit asma dengan upaya pencegahan kekambuhan penderita asmadiperoleh dengan nilai $\mathrm{P}$-value<0,05.

\section{Referensi}

[1] S. Qomar, "Penderita Asmadi Ruang Gardenia RSUD Kabupaten BEKASI Tahun 2018," vol. 8, no. 1, 2018.

[2] GINA, "Pengelolaan Asma dan Pencegahan," 2020.

[3] A. S. Ningrum, A. Muhlisin, and A. Maliya, "Hubungan Pengetahuan Tentang Asma Dengan Upaya Pencegahan Kekambuhan Pada Penderita Asma," Univ. Muhammadiyah Surakarta, 2012.

[4] P. Hidayati, "hubungan antara pengetahaun tentang pencegahan asma dengan kejadian kekambuhan pada penderita asma di Wilayah Kerja Puskesmas Ngoresan Surakarta" vol. 151, pp. 10-17, 2015, doi: 10.1145/3132847.3132886.

[5] Hasmira W. O, "Tinjauan Sikap Keluarga Terhadap Pencegahan Kekambuhan Penyakit Asma," Karya Tulis Ilm., pp. 1-73, 2016.

[6] 2014 Heni Triana, "Hubungan Pengetahuan Pasien Asma Bronkial dengan Upaya Pencegahan kekambuhan Penyakit Asma Bronkial di Rumah Sakit Islam Malahayati Medan," vol. VII, no. 1, pp. 56-64, 2014.

[7] R. Astuti and D. Darliana, "Hubungan Pengetahuandengan Upaya Pencegahan Kekambuhan Asma Bronkhial The Reletionship Between Patients ' Knowledge and Their Effort to Prevent the Bronchial Asthma," vol. IX, no. 1, pp. 9-15, 2018.

[8] E. S. Futriani, "Relationship Of Knowledge Of Diseases Asma With Health Case," no. 3, pp. 114-121, 2018. 


\section{Prosiding Seminar Nasional Kesehatan Lembaga Penelitian dan Pengabdian Masyarakat Universitas Muhammadiyah Pekajangan Pekalongan}

[9] A. H. Al-Zalabani and M. M. Almotairy, "Asthma control and its association with knowledge of caregivers among children with asthma: A cross-sectional study," Saudi Med. J., vol. 41, no. 7, pp. 733-739, 2020, doi: 10.15537/SMJ.2020.7.25167.

[10] Mustika Wati, "Hubungan Tingkat Pengetahuan Orangtua Tentang Asma dengan Frekuensi Kekambuhan Penyakit Asma Pada Anak Usia 6-12 Tahun Di RSUD Panembahan Senopati Bantul Yogyakarta," vol. 151, pp. 10-17, 2015, doi: 10.1145/3132847.3132886. 